\title{
Transradial approach for acute stroke intervention: technical procedure and clinical outcomes
}

\author{
Omaditya Khanna, ${ }^{1}$ Nikolaos Mouchtouris, ${ }^{1}$ Ahmad Sweid, ${ }^{1}$ Nohra Chalouhi, ${ }^{1}$ \\ Ritam Ghosh, ${ }^{1}$ Fadi Al Saiegh, ${ }^{1}$ Michael R Gooch, ${ }^{1}$ Stavropoula Tjoumakaris, ${ }^{1}$ \\ Robert H Rosenwasser, ${ }^{1}$ Victor Romo, ${ }^{2}$ Pascal Jabbour (D) ${ }^{1}$
}

To cite: Khanna 0 ,

Mouchtouris N, Sweid A, et al. Transradial approach for acute stroke intervention: technical procedure and clinical outcomes. Stroke \& Vascular Neurology 2020;5: e000263. doi:10.1136/svn-2019-000263

Received 17 July 2019

Revised 2 October 2019

Accepted 11 November 2019

Published Online First

27 November 2019

\section{Check for updates}

(c) Author(s) (or their employer(s)) 2020. Re-use permitted under CC BY-NC. No commercial re-use. See rights and permissions. Published by BMJ.

${ }^{1}$ Neurosurgery, Thomas Jefferson University Hospital, Philadelphia, Pennsylvania, USA ${ }^{2}$ Anesthesia, Thomas Jefferson University - Center City Campus, Philadelphia, Pennsylvania, USA

Correspondence to

Dr Pascal Jabbour;

Pascal.jabbour@jefferson.edu

\section{ABSTRACT}

Background and purpose Radial artery catheterisation is an alternate route of access that has recently started to gain more widespread use for neuroendovascular procedures, including acute stroke intervention. In this small case series, we present our institution's outcomes in patients undergoing acute stroke interventions via transradial access.

Materials and methods We present a retrospective study of 15 patients who underwent acute stroke intervention via radial artery access. We analyse these patients' periprocedural and clinical outcomes after undergoing mechanical thrombectomy.

Results A total of 15 consecutive patients were included in the study (9 males and 6 females), and all patients were able to successfully undergo mechanical thrombectomy via radial artery access. The mean time of arterial puncture to reperfusion was $50 \pm 28$ min (range: 15-104). A TICl 2b/3 revascularisation was achieved in $13 / 15$ patients $(87 \%)$; a $\mathrm{TICl} 1$ and $\mathrm{TICl} 2 \mathrm{a}$ outcome was achieved on the other two patients. One patient incurred an iatrogenic vessel dissection during the procedure. Eight of out 15 patients $(53 \%)$ had favourable mRS $(0-3)$ at the time of discharge from the hospital.

Conclusion Radial artery catheterisation is technically feasible for performing acute stroke interventions with favourable time to revascularisation and good overall clinical outcomes.

\section{INTRODUCTION}

Radial artery catheterisation has been shown to be a feasible alternative to femoral artery access for performing a wide range of interventional procedures. ${ }^{12}$ Femoral artery catheterisation requires patients to tolerate an uncomfortable procedure, with associated potential complications such as pseudoaneurysm formation, retroperitoneal haematoma, arteriovenous fistula and artery occlusion. ${ }^{3-5}$ Several large scale, multicentre trials and case series have shown that radial artery access is associated with fewer access site complications than the standard transfemoral approach, with better patient satisfaction measures. ${ }^{6-8}$

Radial artery catheterisation has only recently started to gain more credence in the field of neuroendovascular surgery. ${ }^{9-11}$ At our institution, we have transitioned our practice towards performing the majority of our neuroendovascular procedures via a transradial approach, and have recently published our case series that demonstrates its feasibility. ${ }^{1}$ The use of radial artery catheterisation confers a technically favourable alternative to navigate tortuous aortic arches and neck vasculature, and a recent study demonstrated equipoise in outcomes between patients undergoing mechanical thrombectomy via transradial and transfemoral approaches, with similar access-to-reperfusion times and successful revascularisation rates. ${ }^{4}$ As such, we have begun utilising the radial artery approach for our acute stroke intervention.

Herein, we present our institution's consecutive case series of 15 patients who underwent mechanical thrombectomy via radial artery catheterisation. We discuss our technical procedure, as well as clinical outcomes. We hope this study adds to the growing body of literature that encourages the use of radial artery access when performing acute stroke interventions.

\section{METHODS}

\section{Study design}

The study protocol was approved by our Institutional Review Board. The authors declare that all supporting data are present within the article. We conducted a retrospective analysis and identified 15 consecutive patients who underwent treatment for acute stroke via mechanical thrombectomy between December 2018 and April 2019. Patients who presented within 6 hours of symptom onset only received a CT angiogram; those with a large vessel occlusion, with an ASPECTS score of 6 or greater, were deemed candidates for thrombectomy. Patients who presented after 6 hours were evaluated via both CT angiogram and CT perfusion imaging, and those 


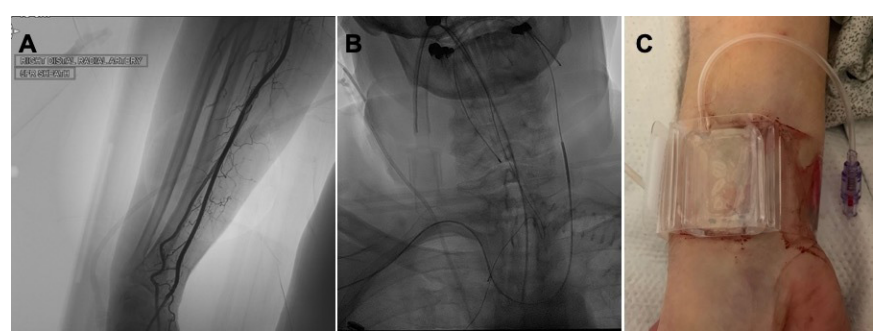

Figure 1 Radial artery access is achieved via ultrasound guidance, using a counter-puncture technique, and a fluoroscopic image is taken to delineate arterial anatomy of the right arm (A). Using transradial access, all vessels of the aortic arch, with various configurations, are able to be catheterized safely and effectively, en route to the desired intracranial vasculature (B). A compression device is applied to the wrist at the conclusion of the procedure for 1 hour, and is gradually deflated as haemostasis is achieved (C).

with a completed infarct of $<50 \%$ on the latter were taken for treatment. We accessed patients' electronic medical record and collected relevant data related to their procedure for analysis.

\section{Radial artery catheterisation technique}

All procedures were conducted using conscious sedation. The right wrist is prepped and draped, and local lidocaine is administered. (Left wrist access is obtained rarely for cases where access to the left vertebral artery is necessary, and unreachable from the right side. However, the specifics of the following technique are pertinent to carotid access; for posterior circulation vessel occlusion, different catheters are usually used.) Radial artery catheterisation is achieved using ultrasound guidance, via double-wall puncture and Seldinger technique. ${ }^{12}$ After access is achieved, a 6 French Cook shuttle sheath (Cook Medical, Bloomington, Indianapolis, USA) is used to catheterise the radial artery, and a radial 'cocktail' consisting of 2000 units of heparin, $5 \mathrm{mg}$ of nicardipine and 200 $\mu \mathrm{g}$ of nitroglycerin is then administered intra-arterially through the sheath. A small skin incision is made over the sheath to facilitate placement of the larger working sheath, and a radial run is then performed to evaluate the vascular anatomy.

Using this run as a roadmap, a 0.038 guidewire (Terumo Interventional Systems, Somerset, New Jersey, USA) is advanced to approximately the level of the brachial artery. A Simmons 2 Selection catheter (Merit Medical, South Jordan, Utah, USA) telescoping inside the 6 French shuttle are introduced into the radial artery all the way to the brachial artery and to catheterise the appropriate common carotid artery. A roadmap from this location enables the wire, selection catheter and then shuttle sheath, to be advanced into the internal carotid artery.

The thrombectomy itself can be performed via a range of devices available, including Solitaire stent-retriever (Medtronic, Minneapolis, Minnesota, USA), Riptide Aspiration System (Medtronic), Penumbra System
(Penumbra, Alameda, California, USA) and Embotrap (Cerenovus, New Brunswick, New Jersey, USA). ${ }^{13}$

After the procedure is complete, the sheath is removed and a radial artery compression device (TR Band, Terumo Interventional Systems) is applied. The compression band is inflated with air, and is slowly, sequentially deflated after 1 hour (figure 1 ).

\section{Statistical analysis}

Data are presented as mean values \pm SD values. Analysis was carried out using unpaired t-test, $\chi^{2}$, Fisher's exact tests and ANOVA, as appropriate. Games-Howell post hoc analysis was utilised in the ANOVA analysis for cohorts without homogeneity of variances. $P$ values of $\leq 0.05$ were considered statistically significant. Statistical analysis was performed using IBM SPSS V.24.0.

\section{RESULTS}

\section{Patient characteristics}

A summary of the study's enrolled patients' demographics and clinical characteristics can be found in table 1. A total of 15 consecutive patients were included in the study (9 males and 6 females). The mean age was 72 years old (range: 59-90). The mean NIH stroke scale (NIHSS) on admission was 14.1 (range: 7-32). Fourteen patients presented with occlusions in the anterior circulation, and one patient presented with a basilar thrombus. The mean time between when the patient was last known well and time to radial artery puncture was 7 hours and $30 \mathrm{~min}$ (range: 2-16hours). Four patients met criteria and were administered r-tPA prior to their thrombectomy intervention.

\section{Procedural outcomes}

The mean time of arterial puncture to reperfusion was $50 \pm 28 \mathrm{~min}$ (range: 15-104). One patient incurred an iatrogenic vessel dissection during the procedure (which was managed via aspirin therapy postoperatively), and the remainder of the procedures were carried out without any complications. All patients intended to be treated via radial artery catheterisation were successful, and no treatment necessitated reverting to femoral artery access to complete the procedure. Postprocedurally, there were no cases on haemorrhagic transformation seen on MRI.

An average of 2 passes were performed in order to achieve desirable revascularisation (range: 1-6). All cases were performed via clot aspiration, and a stent was not necessary in any of the procedures. Thirteen out of 15 patients $(87 \%)$ of patients underwent a TICI $2 \mathrm{~b} / 3$ revascularisation.

\section{Clinical outcomes}

Out of 15 patients, 2 patients (13\%) died during their hospitalisation (they were both transitioned to comfort care per family wishes given their overall poor prognosis for a meaningful recovery); the remaining patients survived their hospitalisation. When excluding for these two deaths, the remainder of patients had significant 
Table 1 Demographics and clinical characteristics for 15 patients presenting with acute ischaemic stroke, treated with mechanical thrombectomy via radial artery access

\begin{tabular}{clllll}
\hline Patient & Sex & $\begin{array}{l}\text { Age } \\
\text { (years) }\end{array}$ & $\begin{array}{l}\text { NIHSS on } \\
\text { admission }\end{array}$ & $\begin{array}{l}\text { Site of } \\
\text { thrombus }\end{array}$ & $\begin{array}{l}\text { Revascularisation } \\
\text { TICl score }\end{array}$ \\
\hline 1 & F & 85 & 7 & Right M1 & $2 \mathrm{~b}$ \\
\hline 2 & F & 59 & 12 & Left M1 & 3 \\
\hline 3 & M & 88 & 25 & Right M1 & 3 \\
\hline 4 & F & 62 & 16 & Left M1 & 3 \\
\hline 5 & M & 90 & 9 & Right M3 & 1 \\
\hline 6 & M & 61 & 17 & Left M1 & 3 \\
\hline 7 & F & 64 & 13 & Right M2 & 3 \\
\hline 8 & M & 84 & 7 & Left M2 & $2 \mathrm{a}$ \\
\hline 9 & M & 71 & 1 & Right M1 & $2 b$ \\
\hline 10 & M & 83 & 26 & Left M1 & 3 \\
\hline 11 & F & 62 & 32 & Basilar & 3 \\
\hline 12 & F & 63 & 10 & Right M1 & 3 \\
\hline 13 & M & 70 & 8 & Right A1 & 3 \\
\hline 14 & M & 62 & 10 & Right A2 & 3 \\
\hline 15 & M & 76 & 18 & Left M1 & 3 \\
\hline
\end{tabular}

NIHSS, NIH stroke scale.

improvement in their NIHSS postoperatively. Six of out 15 patients $(40 \%)$ of patients had favourable modified Rankin score (mRS) $0-2$ at the time of discharge from the hospital; 2 patients had mRS of 3, five patients had mRS of 4 and 5 , and 2 patients were placed on comfort care given poor overall prognosis (figure 2).

\section{DISCUSSION}

Over the last decade, transradial access has become the preferred method of access for cardiac interventionalists, and several large scale randomised, controlled studies have shown that it is a safe and effective means of performing a wide range of procedures. ${ }^{14}$ Despite early case reports detailing the efficacy of the transradial approach, ${ }^{11}{ }^{15}$ the vast majority of practicing neurointerventionalists still prefer femoral artery access. Currently, radial artery access is scarcely used for neuroendovascular procedures, but is starting to gain more widespread use. In the present study, we present our institution's case series of acute stroke intervention performed via transradial access with excellent procedural and clinical outcomes.

Our series includes 15 consecutive mechanical thrombectomy cases performed via transradial access. Interestingly, there was no incidence of ICA occlusion in our small case series. All patients were able to be successfully treated via radial artery catheterisation, and no case required us to revert to femoral puncture in order to complete the procedure. One of the limitations that preclude neuroendovascular practitioners from pursuing transradial access is the perceived difficulty of safely and efficiently navigating the great vessels and cerebral vasculature. ${ }^{11}$ The results of this study further highlight that the devices that are at our disposal are effective to navigate difficult aortic arches and tortuous intracranial vasculature, with overall favourable revascularisation outcomes. ${ }^{1016}$

In acute stroke intervention, the time to reperfusion is paramount in ensuring that patients have the best chance of achieving favourable clinical outcomes. Our results highlight that the overall procedural times for mechanical thrombectomy are, in our experience, comparable to those achieved via traditional femoral access. ${ }^{17} 18$ The average duration of our transradial mechanical thrombectomy was $50 \mathrm{~min}$, and the majority of our procedures were able to be completed within 1 hour. The majority of our interventions yielded TICI scores of $2 \mathrm{~b}$ or 3 , and the one patient in whom only a TICI 1 score was achievable presented with a distal M3 thrombus.
A

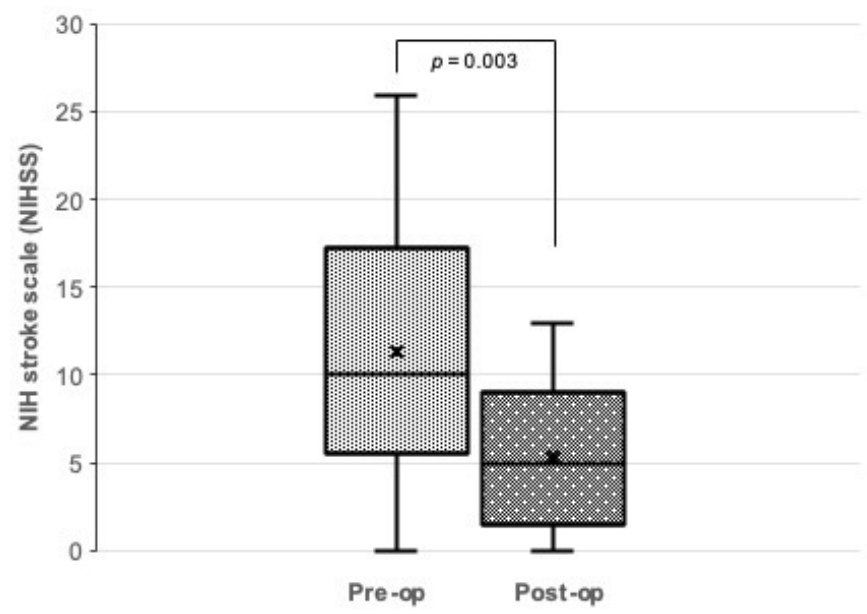

B

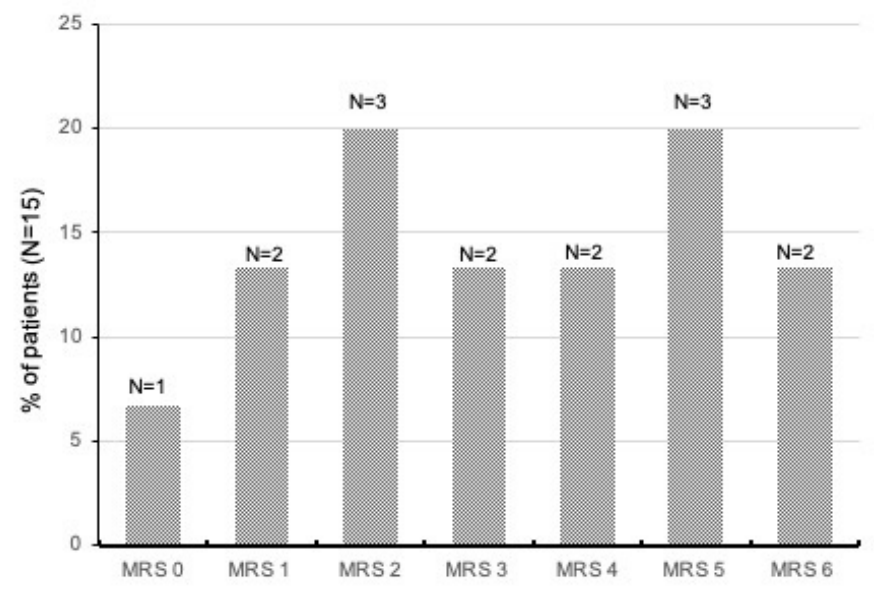

Figure 2 When excluding two patients who were deceased (both made comfort care per family discussion), patients who survived their hospitalisation stay had significantly improved NIHSS post-op (mean 5.31 \pm 4.09 ) compared with at the time of presentation (mean 13.3 \pm 7.3) (A). The $m R S$ scores of $n=15$ patients at the time of discharge from the hospital after undergoing transradial mechanical thrombectomy for acute stroke (B). NIHSS, NIH stroke scale. 
Given that radial artery access has only recently been adopted by neurointerventionalists, there is a paucity of studies that has investigated the safety and efficacy of mechanical thrombectomies performed via transradial access. ${ }^{9}$ Chen et al presented a study of 51 patients, out of which 18 underwent thrombectomy via radial artery access and the remaining 33 via traditional femoral artery access, and found that there was no significant difference in operative times, periprocedural complications or clinical outcomes between the two groups. ${ }^{4}$ Further studies, ideally in the form of a randomised clinical trial, with a larger patient cohort, will need to be performed in order to investigate the equipoise between radial and femoral artery access for acute stroke intervention. Furthermore, we hope to report functional outcomes (mRS scores) at 3-month and 6-month follow-up for this patient cohort.

The field of endovascular neurosurgery has shown that technical innovation improves clinical outcomes and overall patient satisfaction. ${ }^{19}$ In this study, we have shown that acute stroke intervention can be successfully be formed via radial artery catheterisation. As more practitioners adopt the transradial route, not just for stroke intervention, but for treatment of other complex neurovascular pathology, we postulate that there will be an acceleration of novel device development that will aid in achieving even improved outcomes.

\section{CONCLUSION}

Radial approach may be an alternative option for acute ischaemic stroke intervention for select patients with subsequent timely revascularisation and good clinical outcomes. We hope that the results of this study encourage other neurointerventionalists to consider transradial access when performing neuroendovascular procedures. Further studies are needed evaluate the outcomes between stroke interventions performed via radial and femoral artery access, and present long-term patient follow-up functional outcomes.

\section{Twitter Pascal Jabbour @PascalJabbourMD}

Contributors OK, AS, NM and PJ devised the study design. OK, NM and PJ performed statistical analysis. All authors contributed towards the production of manuscript.

Funding Only departmental funding was used to carry out this research study.

Competing interests PJ is a consultant for Medtronic and MicroVention. ST is a consultant for Stryker.

Patient consent for publication Not required.

Ethics approval The institutional ethics committee of the study.

Provenance and peer review Commissioned; externally peer reviewed.

Data availability statement All data relevant to the study are included in the article or uploaded as supplementary information.

Open access This is an open access article distributed in accordance with the Creative Commons Attribution Non Commercial (CC BY-NC 4.0) license, which permits others to distribute, remix, adapt, build upon this work non-commercially, and license their derivative works on different terms, provided the original work is properly cited, appropriate credit is given, any changes made indicated, and the use is non-commercial. See: http://creativecommons.org/licenses/by-nc/4.0/.

ORCID iD

Pascal Jabbour http://orcid.org/0000-0002-8965-2413

\section{REFERENCES}

1 Khanna O, Sweid A, Mouchtouris N, et al. Radial artery catheterization for neuroendovascular procedures. Stroke 2019;50:2587-90.

2 Chen SH, Snelling BM, Shah SS, et al. Transradial approach for flow diversion treatment of cerebral aneurysms: a multicenter study. $J$ Neurointerv Surg 2019;11:796-800.

3 Tavakol M, Ashraf S, Brener SJ. Risks and complications of coronary angiography: a comprehensive review. Glob J Health Sci 2012;4:65-93.

4 Fifi JT, Meyers PM, Lavine SD, et al. Complications of modern diagnostic cerebral angiography in an academic medical center. $J$ Vasc Interv Radiol 2009;20:442-7.

5 Hibbert B, Simard T, Wilson KR, et al. Transradial versus Transfemoral artery approach for coronary angiography and percutaneous coronary intervention in the extremely obese. JACC Cardiovasc Interv 2012;5:819-26.

6 Jolly SS, Yusuf S, Cairns J, et al. Radial versus femoral access for coronary angiography and intervention in patients with acute coronary syndromes (rival): a randomised, parallel group, multicentre trial. Lancet 2011;377:1409-20.

7 Ando G, Capodanno D. Radial versus femoral access in Invasively managed patients with acute coronary syndrome: a systematic review and meta-analysis. Ann Intern Med 2015;163:932-40.

8 Mehta SR, Jolly SS, Cairns J, et al. Effects of radial versus femoral artery access in patients with acute coronary syndromes with or without ST-segment elevation. J Am Coll Cardiol 2012;60:2490-9.

9 Snelling BM, Sur S, Shah SS, et al. Transradial cerebral angiography: techniques and outcomes. J Neurointerv Surg 2018;10:874-81.

10 Chen SH, Snelling BM, Sur S, et al. Transradial versus Transfemoral access for anterior circulation mechanical thrombectomy: comparison of technical and clinical outcomes. J Neurointerv Surg 2019.

11 Levy El, Boulos AS, Fessler RD, et al. Transradial cerebral angiography: an alternative route. Neurosurgery 2002;51:335-42. discussion 40-2.

12 Pancholy SB, Sanghvi KA, Patel TM. Radial artery access technique evaluation trial: randomized comparison of Seldinger versus modified Seldinger technique for arterial access for transradial catheterization. Catheter Cardiovasc Interv 2012;80:288-91.

13 Snelling BM, Sur S, Shah SS, et al. Transradial approach for complex anterior and posterior circulation interventions: technical nuances and feasibility of using current devices. Operative Neurosurgery 2019;17:293-302.

14 Ibanez B, James S, Agewall S, et al. 2017 ESC guidelines for the management of acute myocardial infarction in patients presenting with ST-segment elevation: the task force for the management of acute myocardial infarction in patients presenting with ST-segment elevation of the European Society of cardiology (ESC). Eur Heart $J$ 2018;39:119-77.

15 Matsumoto Y, Hongo K, Toriyama T, et al. Transradial approach for diagnostic selective cerebral angiography: results of a consecutive series of 166 cases. AJNR Am J Neuroradiol 2001;22:704-8.

16 Hess CN, Peterson ED, Neely ML, et al. The learning curve for transradial percutaneous coronary intervention among operators in the United States: a study from the National cardiovascular data registry. Circulation 2014;129:2277-86.

17 Alawieh A, Vargas J, Fargen KM, et al. Impact of Procedure Time on Outcomes of Thrombectomy for Stroke. J Am Coll Cardiol 2019;73:879-90.

18 Spiotta AM, Vargas J, Turner R, et al. The golden hour of stroke intervention: effect of thrombectomy procedural time in acute ischemic stroke on outcome. J Neurointerv Surg 2014;6:511-6.

19 Rosenwasser $\mathrm{RH}$, Lang M, Tjoumakaris S, et al. Disruptive innovation in neurovascular disease. Neurosurgery 2017;64:78-82. 